\title{
Income instability, mobility and distribution
} in Argentina

\author{
Luis Beccaria and Fernando Groisman
}

$\mathrm{T}$

his article analyses changes in the instability of labour incomes in

Greater Buenos Aires between the late 1980s and early 2000s. It aims to study the impact of those changes on different individual and household groups, and then to evaluate the influence of current-income variability on income concentration. For the latter, the average inequality of current incomes is compared with the inequality of average (i.e. more permanent) incomes. The results obtained strengthen the argument for combining cross-section with other data that track the income paths of individuals through time.

Luis Beccaria

Universidad Nacional de General Sarmiento, Argentina

- lbeccari@ungs.edu.ar

Fernando Groisman

National Centre for Scientific and Technical Research (CONICET) Universidad Nacional de General Sarmiento, Argentina 


\section{I}

\section{Introduction}

The distribution of both individual and family incomes in Argentina has become steadily more concentrated since the mid-1970s. This trend lasted throughout the 1980s, which were largely years of instability and stagnation, and into the following decade, despite better macroeconomic performance. ${ }^{1}$

Throughout this period, there were also sharp changes in inflation: very high rates in the 1970s and 1980 s, including hyperinflationary spikes towards the end of the latter decade and in the early 1990s, before substantial price stability was restored in the remainder of the last decade of the twentieth century. As inflation is a key factor in explaining the stability of real incomes, the latter ought to have worsened in the 1970s, and especially in the 1980s, and then should have improved in the following decade. Nonetheless, there is also evidence of high levels of job instability, particularly in the $1990 \mathrm{~s},{ }^{2}$ which also affects income variability at both the individual and household levels.

It is therefore worth making a more in-depth analysis of income instability in Argentina's different macroeconomic situations, given the adverse effects of such instability on individual welfare levels. In particular, instability increases risk and thus diminishes the utility of a given flow of resources; and it can also undermine consumption levels even when predictable.

Instability may go hand-in-hand with mobility, which generally means changes in the relative position of incomes in the distribution, or changes in the distance between them. The existence of a mobility process has an impact on the income distribution. In particular, it could make the degree of concentration, measured by a given year's incomes, overstate inequality in the distribution of more permanent incomes measured as an average over several years. More importantly for the purposes of many diagnostic studies, changes in the degree of mobility may cause changes in current-income inequality to inadequately reflect changes in the inequality of average incomes.

\footnotetext{
$\square$ The authors are grateful for comments by Mariana González, Roxana Maurizio, Paula Monsalve and Valeria Esquivel.

1 See, for example, Altimir and Beccaria (2001).

2 See Hopenhayn (2001), Galiani and Hopenhayn (2000), and Beccaria and Maurizio (2004).
}

Given the importance of income variability for analysing their level and distribution, this paper will examine the changes that have occurred since the late 1980s. Despite the importance of such issues, few studies have addressed them in the past. Moreover, the few analyses that have been undertaken ${ }^{3}$ use a shorter timeframe than considered here; and, in particular, they do not include periods of high inflation. They also fail to explicitly relate the phenomena of instability, risk, mobility and concentration in average incomes.

The research summarized in this article studied the key factors determining instability and its differential intensity between household groups. It also assessed the extent to which changes in instability have affected changes in the income distribution. The aim, therefore, is to explore the hypothesis that an increase in inequality, when studied using data from each period, or cross-section data (i.e. with current incomes) also reflects changes in the distribution of average incomes. To complement this, average household income was adjusted for the effect of variability, and its behaviour was compared with that of unadjusted average income.

The analysis, covering the period 1988-2001, will distinguish four periods that are relatively homogeneous in terms of a set of variables that are important for the aims being pursued. Data for Greater Buenos Aires will be used, since this is Argentina's main metropolitan area and home to nearly one third of the population. The temporal and geographic section chosen reflect the availability of statistical information, since microdata are only continuously available for that region and for those years of household surveys. The study omits 2002-2003, since these are difficult years to analyse with the methodology used in this paper. $^{4}$

\footnotetext{
${ }^{3}$ See Albornoz and Menéndez (2002), Cruces and Wodon (2003), Gutiérrez (2004), and Fields and Sánchez Puerta (2005).

${ }^{4}$ As will be seen below, instability is evaluated from data showing changes in individual incomes over 18-month periods. To include the initial months of 2002 would be heterogeneous in terms of inflation, because they include times of relative stability, thereby making it impossible to adequately characterize this phase. The phase also covers different moments in the dynamic of aggregate output.
} 
Section II, which follows, contextualizes the analysis of mobility in Argentina, by briefly summarizing the behaviour of the macroeconomy and the income distribution. Section III reviews a number of the different approaches to be found in the literature on income dynamics and highlights the various concerns that motivate analysis of this topic. Section
IV sets out the article's specific objectives and describes the analytical methods applied; while section $\mathrm{V}$ describes the data source used. The core of the article consists of sections VI and VII, which describe and analyse the figures for Argentina in terms of variability and mobility, respectively. Section VIII offers conclusions.

II

\section{Macroeconomic behaviour and income distribution since the mid-1970s}

The mid-1970s marked the start of a 15-year period of macroeconomic instability and productive stagnation. Gross domestic product (GDP) was broadly unchanged throughout that period, and inflation remained at high levels (figure 1). This performance was associated with an external constraint arising from the high level of external debt, which in turn was generated by the policies implemented, particularly between 1978 and

FIGURE 1

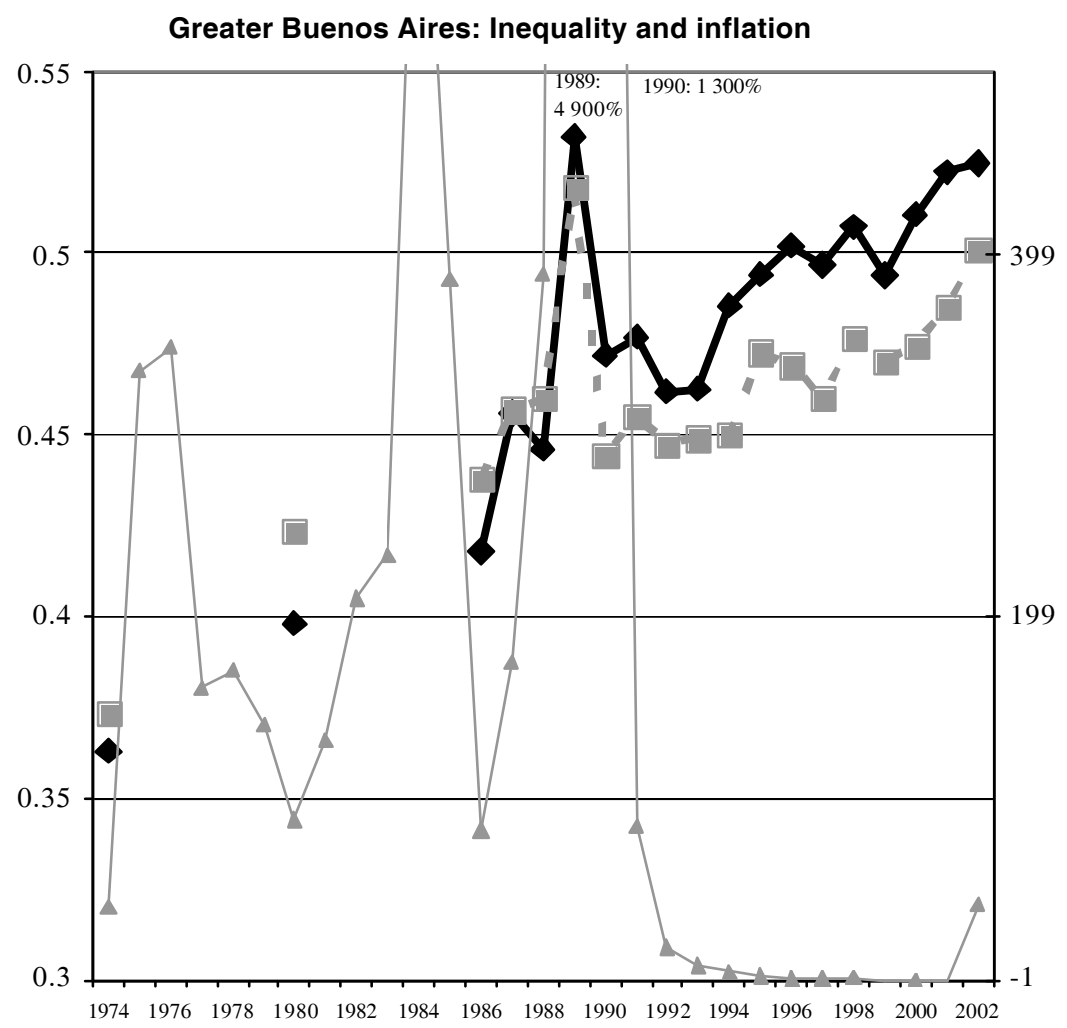

Gini: per capita household income

- Gini: income recipients

Inflation

Source: Authors' estimates on the basis of data provided by the National Institute of Statistics and Censuses (INDEC) 
1981. The measures adopted subsequently -throughout the 1980s- were unable to successfully address a number of structural aspects of the Argentine economy, such as the management of public accounts and the "high inflation regime" (although the two factors are not independent). The latter is very important for understanding both the domestic effects of external borrowing and the difficulties in achieving sustained stabilization.

This process of macroeconomic instability culminated in the hyperinflationary episodes of 1989 and 1990. The Government that took office in 1989 was initially unable to improve the situation, and it was left to the economic team appointed in late January 1991 to implement a stabilization programme that managed to halt inflation and generate activity growth. The cornerstone of that programme was the Convertibility Act, which fixed the exchange rate, established the convertibility of all currency in circulation and prohibited monetary issuance that was not backed by external assets. This measure, together with a number of others implemented in the fiscal and other domains, allowed for a rapid reduction in inflation: the variation in the consumer price index was brought down to $3 \% 5$ in May 1991, and to levels close to $1 \%$ by the end of that year. Stability firstly allowed for an improvement in the purchasing power of wages and, secondly, an expansion of credit. These developments were associated with significant consumption growth, particularly in the case of durable goods and construction. Investments made by privatized enterprises also contributed to the expansion of domestic demand, ${ }^{6}$ while the reduction in inflation made it possible to improve levels of tax revenue.

The vigorous inflow of foreign capital between 1991 and 1994 -attracted by the greater confidence generated by stability and the orientation of economic policy, but also due to a larger supply of funds on the international financial market- boosted the growth of domestic demand. Nonetheless, the Mexican crisis in late 1994 revealed the fragility of an economy in which expansion was based on capital inflows from abroad, although the Argentine recession associated with this event was brief, and the economy resumed a rapid growth path as soon as conditions on the international capital market improved. In 1998, however, when this market became more problematic again and Brazil (a major export destination) went into recession, there was a new downswing in GDP which, unlike the previous episode, lasted an uncommonly long time and triggered abandonment of the fixed exchange rate system shortly after the start of 2002.

The serious macroeconomic instability experienced since the mid-1970s is one of the explanations for the significant deterioration in the income distribution since that time. Initially, the increase in inequality probably stemmed from the differential impact of the rise in inflation in 1975 and 1976 on the relative wages of individuals with different skill levels. Income inequality remained high in the 1980s, with individual incomes maintaining their concentration while family incomes became more concentrated.

Despite an improvement in the macroeconomic setting and the introduction of structural reforms, inequality continued to worsen in the 1990s, except during the initial expansionary phase (1991-1994). Although an in-depth analysis of that trend is beyond the scope of this article, it is crucial to keep in mind the effects of the significant deterioration in the labour market. Unemployment, for example, rose from $6 \%$ at the start of that decade to $12 \%$ in 1994 and $18 \%$ in 2001 ; and it remained at $15 \%$ even during the recovery of 1995-1998. This phenomenon had its greatest effect on wages, employment possibilities and job quality, particularly for the lower skilled.

One consequence of the unsatisfactory employment trend in the 1990s was an increase in job mobility. As mentioned in the introduction, a number of studies report an increase in the quit rate, particularly in non-wage and precarious wage-earning jobs that were not registered with social security. An increase in the proportion of the latter, which displayed less average stability, was an additional factor leading to a shorter average duration of jobs.

\footnotetext{
5 The rate fluctuated around 7\% between October 1990 and January 1991, before rising to $27 \%$ in February as a result of the devaluation and other measures (such as rate hikes).
}

\footnotetext{
${ }^{6}$ The privatization process was implemented rapidly, because in addition to supporting the goal of withdrawing the State from productive activity, capital inflows were essential to support the external and fiscal account balances.
} 


\section{III}

\section{The different aims of studies on income dynamics}

Numerous papers have studied changes in individual and/or family incomes over time, using panel data. Some of these analyse income instability by evaluating its intensity and variation through time, or between groups of individuals, or else by investigating the impact of instability on individual and family welfare. A clearly larger volume of research, however, focuses on income mobility, i.e. changes in the relative position of incomes in the distribution, or in the distances between them, over time. Such studies reflect two types of concern: some investigate the magnitude and characteristics of mobility and how it has changed over time, while others examine the effects of mobility on inequality.

\section{Income mobility}

Many studies analyse the paths of personal or household incomes with a view to evaluating changes in their relative position in the distribution through time. Changes in the ranking of income recipient units in the income distribution are generally referred to as income "mobility".

Income paths can also be tracked for the purpose of analysing the direction and magnitude of the changes they experience, whether or not accompanied by alterations in the ranking. This is known in the specialized literature as "absolute mobility".

The two approaches are complementary and can occur simultaneously and with different intensities: for example, high/low mobility in the ranking can occur in conjunction with a low/high absolute mobility. This depends partly on the inequality that exists in the distribution of current income, because, when inequality is high, the absolute change in income needed to cause a change in the ranking will be greater than in a low-concentration situation.

The proportion of income recipients that change their position in the distribution is normally analysed through matrices that show transitions from one quantile of the distribution to another, between two periods. Although this is the most common procedure in the specialized literature, it has limitations: in particular, it fails to capture changes that take place within the bounds of the selected quantiles. ${ }^{7}$ Some authors have tried to correct these shortcomings, e.g. by making the boundaries of income quantiles flexible (Hills, 1998). Other ways to obtain quantitative evidence of mobility are through measures of association such as the simple and rank correlation coefficients, of Pearson and Spearman, respectively (OECD, 1996). It should be kept in mind, however, that the first of these coefficients is not restricted to changes of rank.

Moreover, both the matrices and the correlation coefficients can only be used to evaluate changes between two periods. They are not suitable for analysing absolute mobility, because transition matrices, for example, do not record income changes that do not entail changes of rank. Accordingly, when a change of rank is not a concern, procedures that specifically quantify the magnitude of the change in incomes are generally used.

For example, Fields (2004) uses the following indicator of absolute variation, where $i$ represents each income recipient, and $y$ represents incomes in $t_{0}=1$ and $t_{1}=2$,

$$
\Omega=(1 / n) \sum_{i=1}^{n}\left|y_{2 i}-y_{1 i}\right|
$$

although an evaluation is also made of the differences between the logarithms of incomes, or a given income recipient's share of the total. These indicators express the degree of mobility without indicating the direction of the change. Including the sign of the change makes it possible to incorporate the direction of the mean variation which is reflected in $\Omega^{*}$.

$$
\Omega^{*}=(1 / n) \sum_{i=1}^{n}\left(y_{2 i}-y_{1 i}\right)
$$

A particular concern is to analyse the extent to which the presence of mobility is associated with income convergence. The latter, also known as

\footnotetext{
${ }^{7}$ It is also a measure that is sensitive to the degree of inequality in the society, and, therefore, is unsuitable for comparison between countries. For example, the same $10 \%$ increase in incomes could represent a quantile change in one country, whereas in another it could mean staying in the same income bracket.
} 
microconvergence, occurs when incomes experience changes that bring them closer to the mean income in the distribution. The analysis in this case usually focuses on the sign of the coefficient $\beta$ in a model such as:

$$
\Delta \ln y_{i}=\alpha+\beta \ln y_{i i}+\varepsilon_{i}
$$

where $\Delta l n y_{i}$ is the difference of the logarithm of income between two periods, $t_{0}$ and $t_{1}$, and $\ln y_{1 i}$ is the logarithm of the initial period. When the coefficient $\beta$ takes a negative (positive) value, there will be convergence towards (divergence from) the mean. ${ }^{8}$ An advantage of regression analysis is that it can include numerous income observations for each recipient and also evaluate the factors driving changes in incomes.

\section{The impact of mobility on inequality}

A second type of research, closely related to the aim of mobility analysis, seeks to evaluate the impact of changes in individual incomes on the income distribution. In particular, it asks whether the degree of inequality measured with cross-section data differs, and by how much, from that corresponding to "permanent" income, measured as average income over several periods.

Much of the literature on income dynamics has focused on estimating the equalizing effect of mobility, to obtain an approximate measurement of more permanent inequality in society. Such studies tend to compare the various inequality indexes calculated from cross-section income data, with indicators based on longer-run incomes. In general, the Shorrocks (1978) methodology has been used, which analyses the intensity of this equalizing effect through an "adjustment of inequality for mobility" index $(R)$ which compares the concentration of average income in the period under consideration with the average of the inequalities of those various observations.

$$
R\left(W_{T}\right)=\frac{I(\bar{w})}{\sum_{t=1}^{T} \eta_{t} I\left(w_{t}\right)}-1
$$

where $I$ is the inequality indicator, $\overline{\mathrm{w}}$ is average income over $T$ periods, $w_{t}$ is income in period $t$, and $\eta_{t}$ is the weighting factor defined as the units' share of total income in period $t$ with respect to the income in the set

\footnotetext{
${ }^{8}$ Sometimes "quantile" regressions are used; see, for example, Fontenay, Gorgens and Liu (2002).
}

of $T$ periods. Fields (2004) argues that if the aim is to evaluate the extent to which mobility altered the inequality measured at a given point in time, the comparison should be made directly between $I\left(w_{1}\right)$ and $I(\bar{w} t)$, i.e. between inequality in initial period and the inequality of average income. $R$ tends to zero as a maximum value when there is no mobility, and decreases as the effect of mobility on the distribution intensifies.

The time period over which more permanent incomes are calculated matters, because the longer the period, the smaller one would expect the differences between average incomes to be.

\section{Changes in the intensity of mobility}

Panel data contribute to a better evaluation of the dynamic of inequality under the hypothesis of changes in the intensity of mobility. But if the latter were constant, measurements of inequality using cross section data would adequately reflect what would happen to the direction of the change in the concentration of more permanent incomes. An increase in static inequality will not imply greater inequity in the distribution of more permanent incomes only if there is a concomitant increase in income mobility. Specifically, as shown by Gottschalk and Danziger (1998), the variance of average incomes is a function of the average of the variances of the distributions of each observation and the average of the covariances between the different observations.

\section{The welfare effect of income instability}

A different concern is to evaluate the intensity of the instability of individual incomes insofar as this diminishes the utility of a given volume of economic resources. In particular, variability increases risk, ${ }^{9}$ and, although it can be anticipated, it can also change utility, particularly in countries with poorly developed credit markets. If two households received the same average income at the end of the year, but one of them had no income for half of that year, whereas the other received $1 / 12$ of its annual income every month, the welfare levels of the two recipients are likely to have been very different.

The evaluation of income fluctuations is generally based on estimating the degree of intertemporal variation around an expected income or observed

\footnotetext{
${ }^{9}$ See Arrow (1970).
} 
average income. The traditional indicator for this purpose is the coefficient of variation, although the variance or mean deviation of the logarithm of incomes (Gottschalk and Danziger, 1998 and Shorrocks, 1978) are also used. Some authors also use the residuals from fixed-effects wage-regression models as a measure of variability (Burgess, Gardiner and others, 2000).

Other procedures use the variability of observed incomes to estimate an "income corrected for fluctuations", which normally entails applying risk functions to estimate an average income which, if fixed, would provide the same utility as that actually received. ${ }^{10}$ This is based on the idea that individuals (i.e. income recipients) are risk-averse; so, the greater the variability of incomes the smaller the utility obtained from them. The utility functions used -strictly concave- are defined by a parameter of aversion to variability, $\rho$, which determines the instability discount suffered by income recipients.
An example of a function that takes account of risk aversion is the following:

$$
v(y)=\left\{\begin{array}{l}
\frac{y^{1-\rho}}{1-\rho} \operatorname{si} \rho \neq 1 \\
\ln Y \text { si } \rho=1
\end{array}\right.
$$

which shows that the utility of a given income decreases as risk aversion (the coefficient $\rho$ ) rises.

In this case, "corrected income" $y^{c}$ (the level of constant income that provides the same utility as the flow of observed incomes) is calculated as follows:

$$
y^{c}=\left[\sum_{t=1}^{T} g(t) y_{t}^{1-\rho}\right]^{\frac{1}{1-\rho}}
$$

where

$$
\sum_{t=1}^{T} g(t)=1
$$

\section{IV}

\section{Objectives and methods}

Given the wide range of interests represented in the literature on income dynamics that make use of panel data, it is worth clarifying here the specific aims of the research whose initial results are presented in this article. Firstly, the degree of instability of real incomes was analysed, since this has an adverse affect on individual and family welfare. Analysis of income variability over short periods is a relatively unexplored topic, probably because it is not a significant phenomenon in the world's leading economies. Nonetheless, in countries such as Argentina, where macroeconomic stability has been a feature throughout much of its modern history, income variability is particularly relevant, irrespective of any distributive impacts -especially, as will be seen, when it seems to persist even in situations of price stability.

Secondly, the research evaluated the degree of income mobility, along with its impact on the distribution of more permanent incomes.

\footnotetext{
10 These procedures stem from distribution analyses based on the social welfare approach formulated by Atkinson (1970). See Cowell (2000).
}

Two analytical approaches were used to measure income instability. The first of these measured the variability of observed current incomes (of individuals and families) around the mean, using the coefficient of variation $\left(C V_{i}\right.$ for individuals and $C V_{h}$ for households).

$$
\begin{gathered}
C V_{i}=\frac{\sqrt{\sum_{t=1}^{T}\left(w_{i t}-\bar{w}_{i}\right)^{2}}}{\bar{w}_{i}}, \text { where } \bar{w}_{i}=\frac{\sum_{t=1}^{T} w_{i t}}{T} \\
C V_{h}=\frac{\sqrt{\sum_{t=1}^{T}\left(y_{h t}-\bar{y}_{h}\right)^{2}}}{y_{h}}
\end{gathered}
$$

where $y_{h t}=\sum_{i=1}^{m} w_{i h t}$

where, $T$ is the number of observations available, and $i$ identifies each of the $m$ household members who were employed in at least one of the four observations.

$$
y_{h}=\frac{\sum_{t=1}^{T} y_{h t}}{T}
$$


Mean variability arises directly from averaging the $C V \mathrm{~s}$ of each individual and household. As the impact of instability was assumed to vary across income recipients and among families (greater impact among less skilled workers and lower-income families), disaggregated estimates were made for both cases, using groups based on the level of schooling of the individual or head of household as a proxy for socioeconomic status.

Steps were also taken to obtain evidence on the importance of phenomena directly related to variability. For example, instability in real individual incomes is associated with changes in hourly pay and with changes in occupational status (employed/ unemployed). The intensity of the latter will change especially when job mobility varies; whereas variations in nominal wages are associated, among other factors, with the degree of price stability, and are likely to be larger and more frequent in inflationary settings. ${ }^{11}$ The time for which a person works can also be specified in greater detail and broken down into two parts: occupational variability and variability of the number of hours a person works while employed.

To demonstrate the impact of some of these variables, a procedure was carried out to identify the variability of incomes when the effects of job instability and the variability of monthly remuneration (which therefore also reflect changes in hours worked) are successively isolated. In the first case, to measure the effect of changes in remuneration, the coefficient of variation of remuneration from the jobs of each individual is calculated, i.e. that arising from positive incomes only, excluding observations corresponding to situations in which the person was not employed $\left(C V^{a o}{ }_{i}\right)$.

$$
c v^{a o_{i}}=\frac{\sqrt{\sum_{t=1}^{n_{i}}\left(w_{i t}-w_{i}^{*}\right)^{2}}}{w_{i}^{*}} \text { for } w_{i t}>0
$$

where $n_{i}$ is the number of observations in which individual $i$ has a positive income (i.e. where) $w_{i t}>0$.

$$
w_{i}^{*}=\frac{\sum_{t=1}^{n} w_{i t}}{n_{i}}
$$

\footnotetext{
11 Nominal hourly incomes can vary merely as a result of changes in earnings from a given job; but they can also vary as a result of moving from one job to another. The impact of this effect was not calculated.
}

To obtain an indicator that isolates changes in remuneration, a coefficient of variation is calculated on values which, when positive, correspond to the first observation in which the person was employed.

$$
c v_{i}^{a r}=\frac{\sqrt{\sum_{t=1}^{T}\left(A_{i t}-w_{i}^{* *}\right)^{2}}}{w_{i}^{* *}}
$$$$
\text { with } A_{i t}=\left\{\begin{array}{l}
w_{i t} \rightarrow w_{i 1}>0 \\
0 \rightarrow w_{i t}=0
\end{array} \quad w_{i}^{* *}=\frac{\sum_{t=1}^{T} A_{i t}}{T}\right.
$$

where $w_{i 1}$ represents remuneration in the first observation with a positive value.

Two factors are assumed to affect the variability of nominal household labour incomes: variations in the number of income earners in the household and variability in the incomes received by them. As these two factors can work in opposite directions they may offset each other, either partially or completely; in the latter case the resultant change in the variability of household incomes is zero. Variations in the number of household income earners may reflect changes in the size of the household, changes in the employment rate of a household in which the number of members does not change, or both factors together. This paper does not distinguish between the causes of such variation.

The magnitude of the instability of remuneration is deduced from the coefficient of variation of the income of each household, calculated assuming the number of employed members $\left(C v^{a o}{ }_{h}\right)$ is unchanged. In this case, household members who were employed at some point had an income imputed to them for period(s) in which they were unemployed, equivalent to that received in the nearest period (either before or after) in which their remuneration was positive, adjusted for the mean variation in incomes between the two periods.

$$
C V_{h}^{a o}=\frac{\sqrt{\sum_{t=1}^{T}\left(y_{h t}^{*}-\bar{y}_{h}^{*}\right)^{2}}}{\bar{y}_{h}^{*}}
$$

where:

$$
\begin{gathered}
\bar{y}_{h}^{*}=\frac{\sum_{t=1}^{T} y_{h t}^{*}}{T} \\
y_{h t}{ }^{*}=\sum_{i=1}^{m} B_{i h t} ; \quad B_{i h t}=\left\{\begin{array}{l}
w_{i h t} \rightarrow w_{i h t}>0 \\
\bar{w}_{i h t} \rightarrow w_{i h t}=0
\end{array} ;\right.
\end{gathered}
$$




$$
w_{t}=\sum_{i=1}^{n} \sum_{h=1}^{H} w_{i h t} ; \overline{w_{i h t}}=w_{i h s}\left(w_{t} / w_{s}\right)
$$

with $s$ being the positive-income period nearest to $t$, while $w_{t}$ is the average wage in period $t, n$ is the number of persons employed in the period, and $H$ is the number of households.

To evaluate the significance of changes in the number of employed persons, the coefficient of variation of family income was calculated, and it was assumed that the monthly remuneration of all employed members remained fixed and equal to the first positive observation in each case $\left(\mathrm{Cv}^{\mathrm{ar}}{ }_{h}\right)$.

$$
C V_{h}^{a r}=\frac{\sqrt{\sum_{t=1}^{T}\left(y_{h t}^{* *}-y_{h}^{* *}\right)^{2}}}{y_{h}^{* *}}
$$

where $y_{h t}^{* *}=\sum_{j=1}^{n} A_{j h t}$

$$
A_{j h t}=\left\{\begin{array}{l}
w_{i h t} \rightarrow w_{i h 1}>0 \\
0 \rightarrow w_{i h t}=0
\end{array}\right.
$$

where $w_{i h 1}$ is the remuneration in the first period with a positive value.

The second analytical approach to income instability recognizes how utility declines when income becomes more variable, using the standard, strictly concave utility function with constant relative risk aversion, to stylize the fact that risk declines with the level of income and increases with variability.

$$
y_{i}{ }_{i}=\left[\frac{1}{n} \sum_{t=s}^{s+n} y_{i t}^{1-\rho}\right]^{\frac{1}{1-\rho}}
$$

where $y^{*}$ is risk-adjusted income, $y$ is the income of the period, $i$ identifies the household, and $\rho$ is the coefficient of risk aversion. The latter was assigned a value of two for the calculation. ${ }^{12}$

This procedure "downgrades" the level of average income obtained by an individual or household through time, when that average has resulted from a variable path.

With regard to income mobility -the second of the stated objectives- its intensity in Argentina, and particularly its variations between the phases identified, was analysed on the basis on household movements between income quintiles. In other words, distribution quintiles were calculated for each of the observations, and each household's position was identified in each case. It was then possible to identify different paths. As noted above, this approach, which analyses paths between income quantiles can be called into question, because it fails to take account of intra-quantile movements, and also because it treats paths involving very different changes in income in the same way. The approach was therefore complemented by analysing correlation coefficients between the household incomes obtained from the four observations, making it possible to evaluate changes in the positions and relative differentials between income recipients in the income distribution. The smaller the correlation, the larger the differences between the incomes obtained by the same households in two periods of time, and, therefore, the greater the mobility of income. The Pearson and Spearman (rank) correlations were used for this.

Lastly, to quantify the influence of mobility on the income distribution, the Shorrocks "adjustment of inequality for mobility" index, mentioned above, was calculated. ${ }^{13}$

\footnotetext{
12 Estimations made with larger coefficients did not alter the results obtained.

${ }^{13}$ Fields and Sánchez Puerta (2005) and Albornoz and Menéndez (2002) address a similar topic to mobility, by analysing the
}

relation between the intensity of the change in incomes and their level, using the models represented in equation (3). They also examine the relation between mobility and inequality. 


\section{V}

\section{The database used}

Evaluating income instability and mobility, along with their impact on levels and changes in the distribution of income, is only possible when longitudinal data are available, i.e. data showing the different incomes received by the same person or household through time. Although Argentina does not undertake longitudinal surveys, the permanent household survey (ЕРH), performed regularly by INDEC, ${ }^{14}$ provides data of that type that are useful for analysing these issues.

Although EPH does not directly investigate changes in the variables through time, it is possible to construct data of this type because its sample panel rotates, and households are interviewed on four successive occasions. Consequently, by comparing the situation of an individual in those four "waves" one can deduce the changes experienced in a number variables, including income and employment. EPH data were used showing the changes experienced in incomes, activity status and occupation for each income unit (individual or household). Units can also be characterized by a series of sociodemographic and employment attributes.

The EPH sample consists of four rotation groups, one of which enters and another exits in each of the two "waves" made each year (in May and October). On each occasion, therefore, $25 \%$ of the sample is renewed, so $75 \%$ of cases can be compared between two successive waves. Accordingly, if one wanted to track households for the maximum possible time, i.e. during the four waves in which they remain in the survey during an 18-month period, it would only be possible to evaluate a subset representing $25 \%$ of the total sample. The proportion of households and individuals actually reinterviewed is less than these amounts, however, because cases fall by the wayside -a degree of natural reduction (attrition) - for various reasons, such as households leaving the panel or changing address, or difficulties arising in the field work. As the sample size was insufficient, a commonly used procedure was employed to construct bases by pooling rotation groups that entered the sample at different points in time. ${ }^{15}$ This means that individuals (and

14 For a description of the EPH methodology, see www.indec.gov.ar. The survey scheme was changed substantially in 2003. households) who responded to the survey at different times were considered simultaneously: in other words, the method aggregates changes that occurred in neighbouring but different periods.

The data used refer to Greater Buenos Aires only, ${ }^{16}$ since microdata are not available for the other zones included in the survey. In any event, the evolution of the employment situation and income distribution in the metropolitan area has not differed from that experienced in other urban zones, so the conclusions to be reached here may reasonably be extrapolated to the whole set of regions. ${ }^{17}$

To analyse income paths, panel data were prepared for each of the four stages identified. The following scheme shows the different rotation groups for each case. Table 1 shows the number of individuals who were employed at some point in time, and the households corresponding to each phase.

Comparing successive waves of the survey underestimates the number of changes that actually occurred, because transitions are being identified by comparing two observations roughly six months apart. Accordingly, individuals could make two or more movements in the interval between the two waves (e.g. from inactivity to unemployment and vice-versa), without these movements being captured.

It should also be noted that the procedure only analyses the subset of incomes obtained by household members as a result of their labour-market participation as wage earners, own-account workers or employers. This restricted definition of income facilitates a clearer relation between the dynamics of inequality and income instability and the labour-market factors that appear as their determinants. Household income is, consequently, measured by adding together the labour incomes of all employed members. It also needs to be

\footnotetext{
15 Although this procedure makes it possible to work with a large number of observations, the phenomenon of attrition can introduce sample biases which have not yet been investigated. 16 This is Argentina's main urban agglomeration, accounting for $30 \%$ of the country's population and $40 \%$ of its total urban inhabitants.

${ }^{17}$ See, for example, Beccaria, Esquivel and Maurizio (2002).
} 
TABLE 1

Greater Buenos Aires: rotation groups comprising the sample in each phase

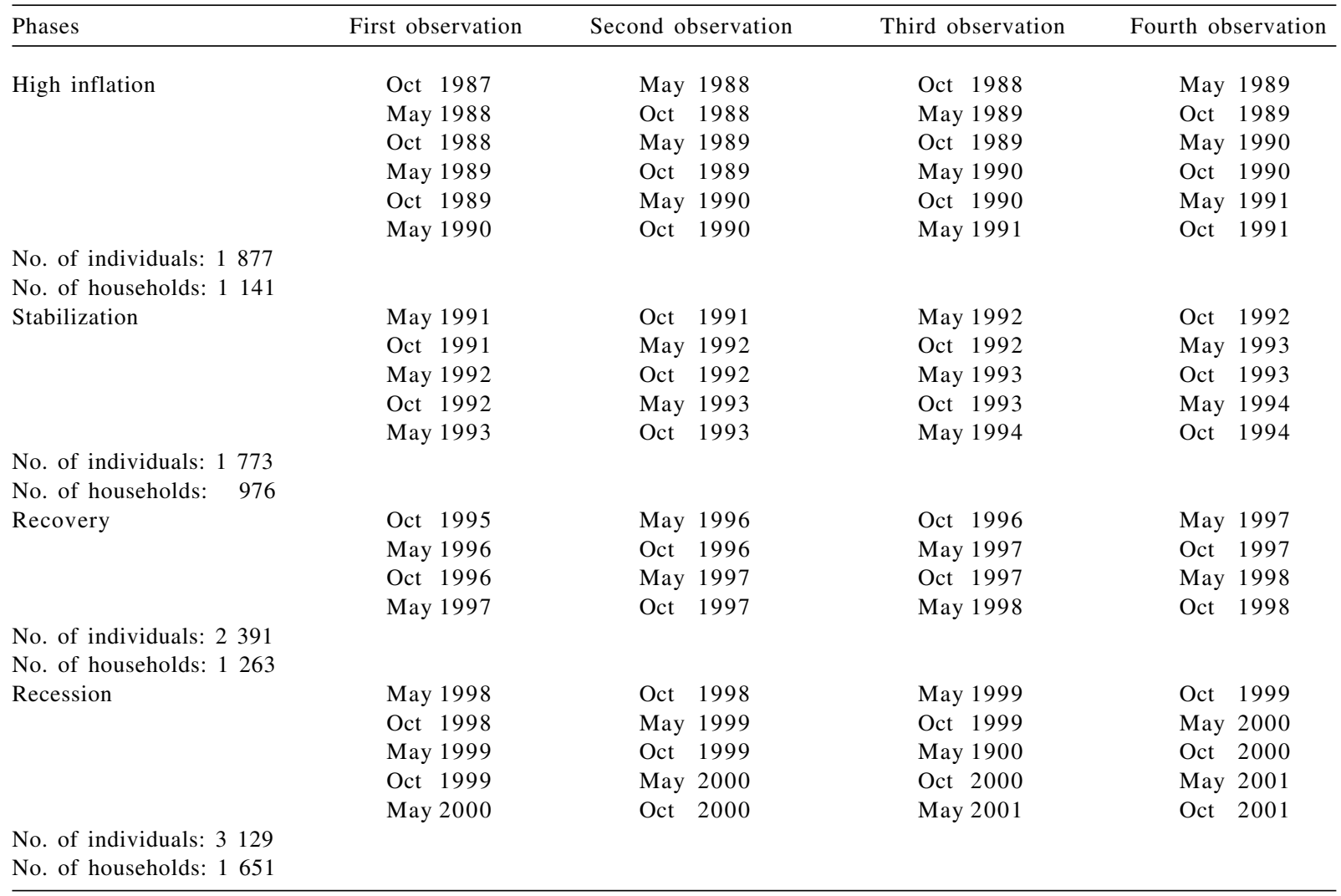

Source: Authors' estimates on the basis of data from the Permanent Household Survey (EPH).

borne in mind that the household survey used here, as is true of many others in the region, does not adequately capture -and significantly under-records- the current resources that households obtain from their ownership of capital. Evidence of this is the similarity of changes recorded by indicators of inequality in total and labour income. Similarly, the universe of households that were studied was limited to those headed by individuals not over 65 years old.
When studying the instability of individual labour incomes, the analysis included persons who were employed in at least one of the observations, i.e. those who registered some positive income from employment.

To obtain results in terms of the instability of purchasing power, which is the relevant concept, nominal values were corrected for variations in the consumer price index (CPI). 


\section{VI}

\section{Income instability in Argentina in the 1990s}

This section addresses one of the article's two objectives, namely to study income instability and its effects on the level of welfare. The first part analyses changes in the degree of variability of incomes, their sources and the effect on different groups of workers and households. The second part reviews the impact on welfare and changes therein during the period under analysis.

\section{Instability of individual and household incomes}

(a) Instability of individual incomes

As shown in table 2, there were no significant changes in the coefficient of variation of labour incomes among individuals who were employed at some time during the four phases analysed. This result

TABLE 2

Greater Buenos Aires: coefficient of variation of incomes of persons who were employed at some time

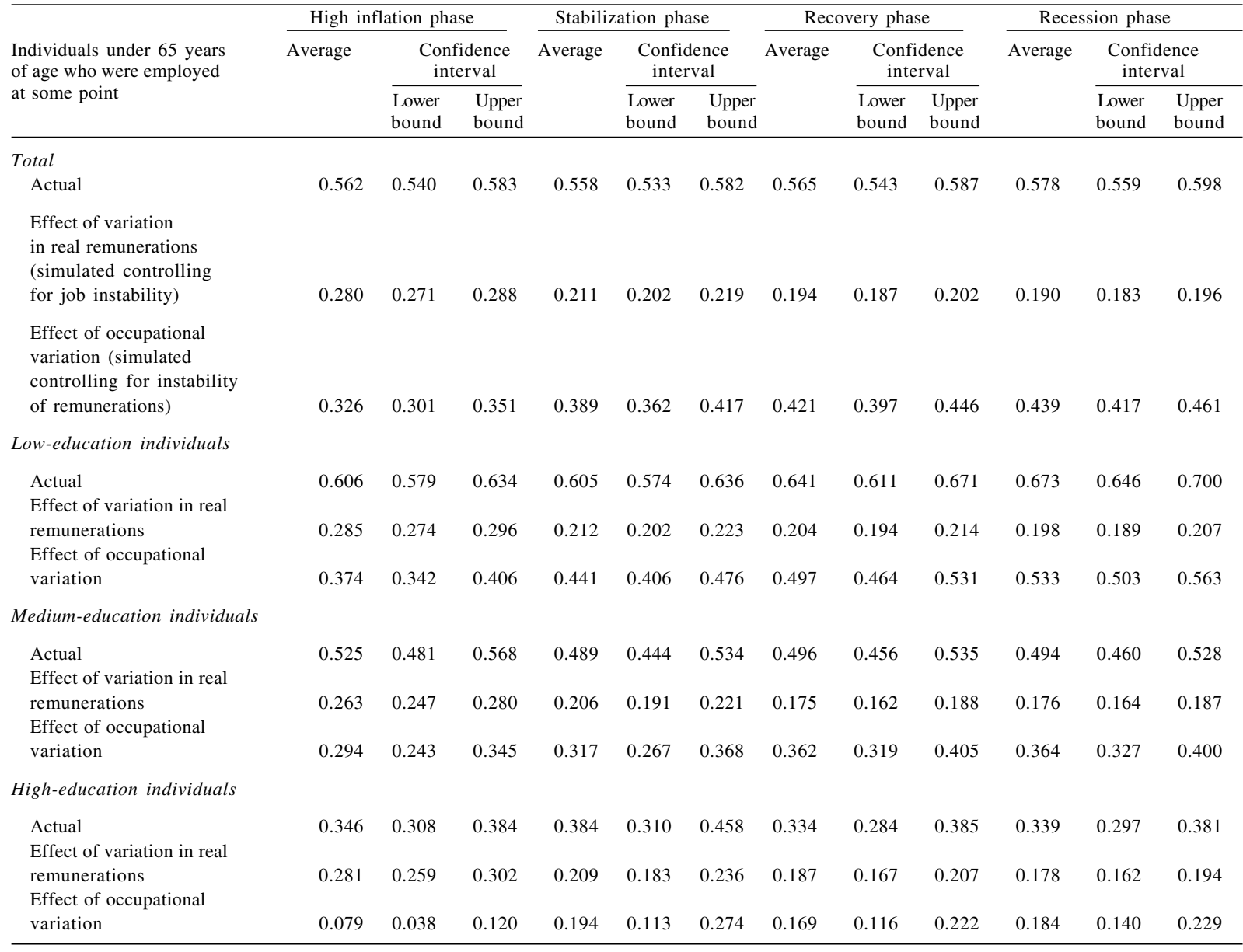

Source: Authors' estimates on the basis of data from the Permanent Household Survey (EPH). 
is curious because, contrary to expectations, the sharp drop in inflation that occurred between the first of those periods (covering the years before the Convertibility Act) and the other three did not affect the average variability of current incomes. As mentioned above, inflation influences the variability of an individual's real labour income through time, via its impact on changes in the remuneration obtained in a given job. Thus, the drop in inflation -especially from such high rates as those recorded between 1987 and 1991- helped to reduce the instability of real wages. This is also shown in table 2 , which evaluates income variability when the effects of job instability are isolated: the coefficient of variation of labour remuneration -considering only positive incomes and excluding observations corresponding to situations in which the person was not employed-falls in the second period compared to the first, and again in the next one. ${ }^{18}$ At the same time, however, income variability associated with job instability increased, as can be deduced from the increase in the coefficient of variation of incomes, controlling for changes in remuneration.

It can be concluded, therefore, that the average variability of incomes among individuals who were employed at some point remained constant throughout the period, despite the significant drop in inflation achieved since the early 1990s. This does not mean that more stable prices have not had the expected effects in terms of stabilizing the purchasing power of remunerations, but those effects were counteracted by events in the labour market that increased job instability.

Another way to verify this is to note that, in the late 1980 s, $69 \%$ of those who were employed at some point had been employed in all four observations, whereas the proportion decreases by five percentage points in the following phase. This trend continued, albeit less intensively, in the next two phases; and, as a result, the proportion of employed persons with stable income paths shrank by 10 percentage points between the beginning and end phases.

\footnotetext{
18 As mentioned in note 16 , the effects of variations in remuneration arising from changes of job or hours worked by individuals that remain employed are not isolated. Accordingly, income variability arising from job factors (controlling for variations in real wages) could be even greater if these effects are incorporated. It should also be noted that an additional source of income variability is data or measurement error in respect of declared incomes. An exercise that excluded cases in which this error may have occurred (i.e. changes in income not associated with changes of occupation or hours worked) did not alter the results obtained.
}

A least-squares model was applied to evaluate the extent to which certain individual and household variables were associated with instability of income and its occupational and remuneration components. Status in terms of education, ${ }^{19}$ head of household, age and gender are considered usually to have a direct effect on income variability or some of its determinants. ${ }^{20}$ Table 3 shows that all these attributes were generally significant and had the expected signs. Negative and positive signs are confirmed in the case of age and age squared, respectively, reflecting the expected influence of the life cycle: instability declines as the age advances, but at a decreasing rate. Only when the dependent variable is "pure" remuneration variability, however, is the low education coefficient not significant in the first period, thereby indicating that the effects of inflation were felt by the employed population at large. This situation was repeated following the stabilization of prices in the early 1990s, i.e. during the stabilization phase, which also shows that the process would have benefited all individuals, independently of other attributes. In the other two phases, however, the low education coefficient was significant, suggesting that instability declined by less among such individuals, or even increased.

Among low-skilled employed persons, income instability was greater towards the end of the period analysed than at the start. This is shown directly in table 2 and can also be deduced from the model reported in table 3 for each of the four periods. ${ }^{21}$ The significance of this result, however, emerges from an exercise (values not shown here), in which a similar model was applied to the set of observations in the four periods for loweducation individuals only, with dummy variables representing the different phases. The dummy variable corresponding to the recessionary phase (1998-2001) was positive and significant with respect to the first phase (high inflation, considered as the base), but this was not the case with the those representing the other two phases.

\footnotetext{
19 Stratification according to educational level was as follows: Low education encompasses those with incomplete secondary schooling; medium education represents those with up to tertiary education incomplete; and high education those that had completed the latter. In the least-squares analysis, a dummy variable was used for low education, which was given the value of 0 for the medium and high education levels.

20 There is ample evidence of the influence of those variables on job instability; see, for example, Farber (1999) and Nickel, Jones and Quintini (2000).

21 A similar result was obtained by Gutiérrez (2004) for the recessionary period $1998-2002$.
} 
TABLE 3

Greater Buenos Aires: estimation of factors determining income instability ${ }^{a}$

\begin{tabular}{|c|c|c|c|c|}
\hline & High inflation phase & Stabilization phase & Recovery phase & Recession phase \\
\hline \multicolumn{5}{|c|}{ Dependent variable: Effective coefficient of variation } \\
\hline Low education & 0.155 & 0.166 & 0.202 & 0.241 \\
\hline Male & -0.201 & -0.228 & -0.154 & -0.149 \\
\hline Age & -0.051 & -0.030 & -0.056 & -0.053 \\
\hline Age squared & 0.001 & 0.000 & 0.001 & 0.001 \\
\hline Head & -0.129 & -0.240 & -0.165 & -0.159 \\
\hline Constant & 1.582 & 1.198 & 1.638 & 1.610 \\
\hline \multicolumn{5}{|c|}{ Dependent variable: Simulated coefficient of variation, controlling for job instability } \\
\hline Low education & $0.015^{\mathrm{b}}$ & $0.000^{\mathrm{b}}$ & 0.020 & 0.015 \\
\hline Male & $0.017^{\mathrm{b}}$ & 0.035 & 0.022 & 0.021 \\
\hline Age & 0.008 & $0.000^{\mathrm{b}}$ & 0.004 & $0.003^{\mathrm{b}}$ \\
\hline Age squared & 0.000 & $0.000^{\mathrm{b}}$ & $0.000^{\mathrm{b}}$ & $0.000^{\mathrm{b}}$ \\
\hline Head & $0.019^{\mathrm{b}}$ & 0.029 & $0.011^{\mathrm{b}}$ & $0.016^{\mathrm{c}}$ \\
\hline Constant & 0.096 & 0.174 & 0.083 & 0.098 \\
\hline \multicolumn{5}{|c|}{ Dependent variable: Simulated coefficient of variation, controlling for remuneration instability } \\
\hline Low education & 0.068 & 0.094 & 0.099 & 0.110 \\
\hline Male & -0.114 & -0.157 & -0.093 & -0.086 \\
\hline Age & -0.048 & -0.021 & -0.050 & -0.052 \\
\hline Age squared & 0.001 & 0.000 & 0.001 & 0.001 \\
\hline Head & $-0.045^{b}$ & -0.122 & -0.112 & -0.086 \\
\hline Constant & 1.111 & 0.706 & 1.200 & 1.230 \\
\hline
\end{tabular}

Source: Authors' estimates on the basis of data from the Permanent Household Survey (EPH).

a Unless otherwise indicated, the coefficients are significant at the $5 \%$ level.

b Not significant at $5 \%$.

c Not significant at $10 \%$.

In contrast, there were no significant differences when the exercise was repeated for higher-education individuals. Table 2, above, shows the increase in instability for the low-education group, which remains unchanged for the other two groups.

This procedure was also used to analyse the significance of variations in income instability among the different educational groups, associated either with fluctuations in remuneration or with occupational status. Among individuals with little schooling, occupational variability was already increasing at the start of the 1990s while pure income instability was not changing significantly. In contrast, the other group did not show changes in either measure.

As the foregoing analysis shows, not only does the individual income variability among people employed at some point in time differ according to their level of schooling, but its persistence between the phases analysed conceals different behaviour patterns between groups defined in this way. The coefficients of variation of incomes in the medium and high education strata (table 2 ) were broadly unchanged throughout the four periods, whereas the less educated experienced even greater income instability in the final period than in the high-inflation phase.

\section{(b) Instability of household incomes}

We now consider the variability of household incomes, which is important not only for the analysis but also to evaluate the extent to which this was affected by the instability of labour incomes received by individuals who were employed at some point. The relation will not necessarily be direct, since it could have been offset by the effect of other variables.

Table 4 shows a significant decrease in the coefficient of variation (18\%) of household labour incomes, between 
TABLE 4

Greater Buenos Aires: coefficients of variation of real labour incomes of households and number of employed

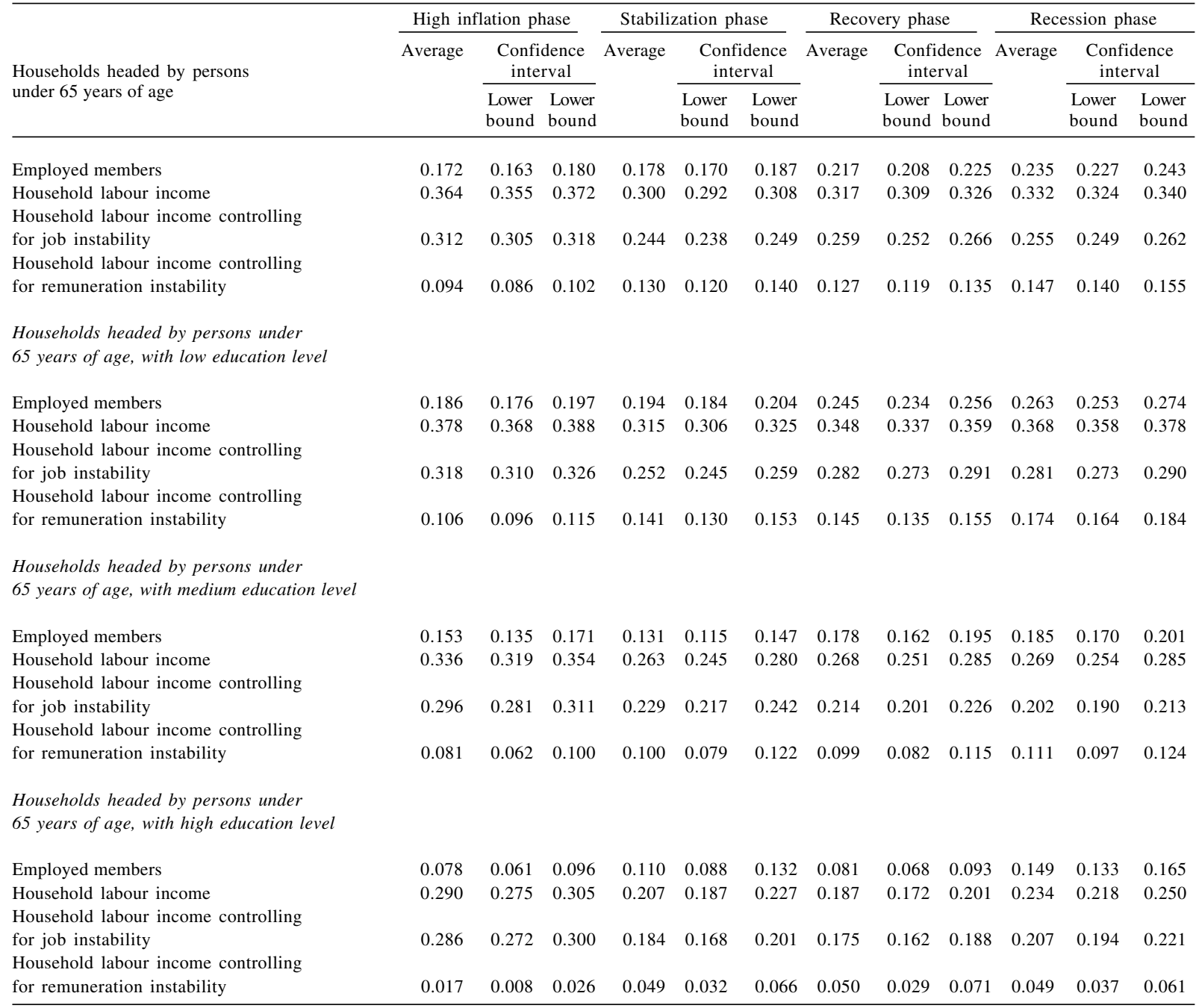

Source: Authors' estimates on the basis of data from the Permanent Household Survey (EPH).

the first and second periods in the early 1990s, resulting from an increase in average job instability among households and a decrease in the variability of remuneration. Then, during the expansionary and recessionary phases that followed the middle of the decade, family income variability increased again (by $6 \%$ and $5 \%$ respectively) on the back of rising job instability. Nonetheless, the variability of family labour incomes in the last of the periods was $9 \%$ less than the value recorded in the late 1980s; and although this aggregate result conflates significantly different experiences across strata defined by the education level of household heads, on average it reflects a different situation than for individual income variability.

The relevance of growing job instability is revealed by a persistent rise in the coefficient of variation of family incomes calculated after controlling for changes in variations in the remuneration of employed household members (table 4). This rose by $38 \%$ with the stabilization in the early 1990 s, whereas the pure real remuneration change decreased by $22 \%$. Considering the two end phases, however, the differences between the two measures were greater: income variability caused by job instability increased 
by $56 \%$, whereas that stemming from fluctuations in remunerations was $18 \%$ below the level recorded in the years of high inflation. In keeping with the analysis of individual incomes, income variability associated with job instability increased most in households headed by individuals with low levels of schooling.

It should be kept in mind that the procedure used to measure variability caused by job changes also captures effects arising from the strategies deployed by household members in response to events affecting them. Specifically, substitution and complementarity mechanisms operate among active members within households; and these affect income instability through both jobs and remuneration, with the final outcome depending on which effect prevails. ${ }^{22}$ A clear example of this is the change in income that can be associated with "perfect" substitution of employed household members (i.e. if one member becomes unemployed, another finds a job). If the income of the new worker is different than that of the family member who becomes unemployed, household income is altered without any change in the number of employed members; this change should be attributed to the job factor and not to fluctuations in remunerations.

The variability of real household incomes was calculated in the same way as the instability of individual incomes, with determinants including the socioeconomic attributes of the head of household such as sex, level of schooling (low education), age, age squared; and variables reflecting household composition, such as size and the presence of members under 18 years of age (table 5).

The variability of household labour incomes is negatively related to the education level of the head of household, and this relation strengthens as from the second expansionary phase. Other factors that had a significant influence were age, with a negative sign, and age-squared, with a positive sign; whereas the coefficient of household size and the presence of children was associated with greater variability throughout the 1990s.

In addition to applying least-squares analysis to overall income instability, the influence of these independent variables on the number of employed household members was also studied, along with that arising from the variation of remunerations among those members. The same model was also estimated for the case of pure income variability, which takes

\footnotetext{
${ }^{22}$ See Beccaria and Groisman (2005).
}

account of changes in the number of employed family members. The education level of heads of household also seems to negatively affect the variability of income recipients, income instability associated with occupational variability and pure income instability.

Table 4 showed that the reduction in the instability of family incomes associated with the control of inflation affected heads of household with different educational levels. Nonetheless, the pattern became more divergent following the post-1995 recovery, with variability increasing among households headed by individuals with low levels of schooling, whereas in other groups no changes were recorded after the reduction associated with stabilization. This broadly reflects what happened with the variability of employed household members, which increased more in the first group. Among these, the pure variability of remunerations also increased while remaining unchanged for the other groups. The changes in the coefficient of the variable "head of household with low education" between the second and third phases (table 5) also shows the uneven behaviour of instability across households from different strata.

Towards the end of the 1990s, therefore, a difference had emerged in levels of household income instability, which was even greater than that recorded at the start of the decade. Although, in the case of variability of the number of income recipients, the gap between high and low strata households was narrowed by the sharp increase in the former during the recessionary phase, differentials in remuneration variability widened.

The foregoing analysis on individual and family income instability can be summarized by stating that it decreased in the second of the phases identified (from the early 1990s) as a result of macroeconomic stabilization. Nonetheless, in the middle of that decade, occupational paths started to become more unstable; and, in the final phase considered, real household incomes became highly unstable, thereby partly losing the benefit of the drop in inflation. This was particularly true among households headed by low-education individuals, in which the additional job instability fully offset the lesser instability of remunerations.

\section{Instability and welfare}

As noted above, fluctuations in the flow of resources received by households are damaging, because they generate uncertainty regarding future values, which may affect levels of consumption and the programming 
TABLE 5

Greater Buenos Aires: estimation of the determinants of household income and job instability ${ }^{a}$

\begin{tabular}{|c|c|c|c|c|}
\hline \multicolumn{2}{|c|}{ High inflation phase } & Stabilization phase & Recovery phase & Recession phase \\
\hline \multicolumn{5}{|c|}{ Dependent variable: effective coefficient of variation of labour incomes } \\
\hline Age & -0.010 & -0.011 & -0.007 & $-0.006^{\mathrm{b}}$ \\
\hline Age squared & 0.000 & 0.000 & 0.000 & 0.000 \\
\hline Male head of household & $-0.007^{\mathrm{c}}$ & $-0.011^{\mathrm{c}}$ & -0.001 & $-0.017^{b}$ \\
\hline \multicolumn{5}{|l|}{ Head of household with } \\
\hline low education level & 0.049 & 0.053 & 0.091 & 0.094 \\
\hline Size of household & $-0.007^{\mathrm{c}}$ & -0.036 & -0.027 & -0.026 \\
\hline \multicolumn{5}{|l|}{ Children up to 18} \\
\hline years of age & 0.014 & 0.048 & 0.043 & 0.048 \\
\hline Constant & 0.496 & 0.449 & 0.376 & 0.360 \\
\hline
\end{tabular}

Dependent variable: coefficient of variation of employed household members

\begin{tabular}{|c|c|c|c|c|}
\hline Age & -0.009 & $0.001^{\mathrm{c}}$ & -0.001 & $-0.001^{\mathrm{c}}$ \\
\hline Age squared & 0.000 & $0.000^{\mathrm{b}}$ & $0.000^{\mathrm{c}}$ & $0.000^{\mathrm{c}}$ \\
\hline Male head of household & $-0.006^{c}$ & $-0.010^{\mathrm{c}}$ & $-0.003^{c}$ & -0.027 \\
\hline $\begin{array}{l}\text { Head of household } \\
\text { with low education level }\end{array}$ & 0.048 & 0.052 & 0.085 & 0.073 \\
\hline Size of household & $0.002^{\mathrm{c}}$ & -0.026 & $-0.001^{\mathrm{c}}$ & $0.000^{\mathrm{c}}$ \\
\hline $\begin{array}{l}\text { Children up to } 18 \\
\text { years of age }\end{array}$ & $-0.001^{\mathrm{c}}$ & 0.032 & $0.010^{\mathrm{b}}$ & 0.012 \\
\hline Constant & 0.253 & $0.047^{\mathrm{c}}$ & $0.104^{c}$ & 0.143 \\
\hline
\end{tabular}

Dependent variable: coefficient of variation of labour income controlling for occupational variability

\begin{tabular}{|c|c|c|c|c|}
\hline Age & -0.004 & -0.007 & $-0.004^{\mathrm{c}}$ & $-0.004^{\mathrm{c}}$ \\
\hline Age squared & $0.000^{\mathrm{b}}$ & 0.000 & $0.000^{\mathrm{b}}$ & 0.000 \\
\hline Male head of household & $-0.014^{b}$ & $-0.005^{\mathrm{c}}$ & $0.002^{\mathrm{c}}$ & $-0.007^{\circ}$ \\
\hline Head of household & & & & \\
\hline with low education level & 0.021 & 0.027 & 0.069 & 0.067 \\
\hline Size of household & -0.019 & $-0.005^{c}$ & -0.012 & -0.015 \\
\hline $\begin{array}{l}\text { Children up to } 18 \\
\text { vears of age }\end{array}$ & 0.032 & 0.013 & 0.022 & 0.030 \\
\hline Constant & 0.388 & 0.338 & 0.273 & 0.260 \\
\hline
\end{tabular}

Dependent variable: coefficient of variation of labour incomes controlling for variability of remunerations

\begin{tabular}{|c|c|c|c|c|}
\hline Age & -0.008 & -0.008 & $-0.005^{c}$ & $-0.004^{c}$ \\
\hline Age squared & 0.000 & 0.000 & $0.000^{\mathrm{b}}$ & $0.000^{\mathrm{c}}$ \\
\hline Male head of household & $0.008^{c}$ & $-0.009^{c}$ & $-0.001^{\mathrm{c}}$ & $-0.016^{b}$ \\
\hline $\begin{array}{l}\text { Head of household } \\
\text { with low education level }\end{array}$ & 0.036 & 0.032 & 0.052 & 0.069 \\
\hline Size of household & 0.026 & -0.020 & $-0.003^{c}$ & $-0.003^{c}$ \\
\hline $\begin{array}{l}\text { Children up to } 18 \\
\text { years of age }\end{array}$ & -0.029 & 0.032 & 0.013 & 0.016 \\
\hline Constant & 0.130 & 0.170 & 0.179 & 0.158 \\
\hline
\end{tabular}

Source: Authors' estimates on the basis of data from the Permanent Household Survey (EPH).

${ }^{\text {a }}$ Unless indicated otherwise, the coefficients are significant at the 5\% level.

b Not significant at $5 \%$.

c Not significant at $10 \%$.

of expenses, or cause difficulties in cushioning the effects even when variability can be anticipated. As described in the methodology section (section IV), taking account of this factor requires the use of utility functions to estimate an income corrected for the effects of fluctuations. This risk correction is also used even when variability has always been rising or falling. Nonetheless, as noted below (section VII, part one), households with rising paths represent less than $5 \%$ of all cases. 
The results confirm that adjusted income grew by more than measured income between the ends of the period, thanks to the reduction in the variability of real incomes noted above. Nonetheless, this improvement differed in intensity across groups; among low- education households, the average increase in both income measures was similar, whereas in households headed by individuals with higher levels of schooling, the risk-adjusted increase rose by $52 \%$, compared to a $29 \%$ rise in average actual incomes (table 6). ${ }^{23}$

TABLE 6

Household labour income: Actual average and risk-adjusted average (in 2001 pesos)

\begin{tabular}{|c|c|c|c|c|c|c|c|c|c|c|c|c|}
\hline \multirow{3}{*}{$\begin{array}{l}\text { Households headed by } \\
\text { persons under } 65 \text { years old }\end{array}$} & \multicolumn{3}{|c|}{ High inflation phase } & \multicolumn{3}{|c|}{ Stabilization phase } & \multicolumn{3}{|c|}{ Recovery phase } & \multicolumn{3}{|c|}{ Recession phase } \\
\hline & \multirow[t]{2}{*}{ Average } & \multicolumn{2}{|c|}{$\begin{array}{l}\text { Confidence } \\
\text { interval }\end{array}$} & \multirow[t]{2}{*}{ Average } & \multicolumn{2}{|c|}{$\begin{array}{l}\text { Confidence } \\
\text { interval }\end{array}$} & \multirow[t]{2}{*}{ Average } & \multicolumn{2}{|c|}{$\begin{array}{l}\text { Confidence } \\
\text { interval }\end{array}$} & \multirow[t]{2}{*}{ Average } & \multicolumn{2}{|c|}{$\begin{array}{c}\text { Confidence } \\
\text { interval }\end{array}$} \\
\hline & & $\begin{array}{l}\text { Lower } \\
\text { bound }\end{array}$ & $\begin{array}{l}\text { Lower } \\
\text { bound }\end{array}$ & & $\begin{array}{l}\text { Lower } \\
\text { bound }\end{array}$ & $\begin{array}{l}\text { Lower } \\
\text { bound }\end{array}$ & & $\begin{array}{l}\text { Lower } \\
\text { bound }\end{array}$ & $\begin{array}{l}\text { Lower } \\
\text { bound }\end{array}$ & & $\begin{array}{l}\text { Lower } \\
\text { bound }\end{array}$ & $\begin{array}{l}\text { Lower } \\
\text { bound }\end{array}$ \\
\hline Risk-adjusted & 597 & 564 & 630 & 874 & 823 & 925 & 855 & 804 & 905 & 851 & 806 & 895 \\
\hline Actual & 707 & 669 & 746 & 982 & 926 & 1037 & 958 & 911 & 1005 & 950 & 909 & 992 \\
\hline \multicolumn{13}{|c|}{$\begin{array}{l}\text { Households headed by person } \\
\text { of low education level }\end{array}$} \\
\hline Risk-adjusted & 433 & 411 & 454 & 682 & 646 & 718 & 591 & 561 & 621 & 576 & 544 & 609 \\
\hline Actual & 520 & 495 & 545 & 788 & 753 & 824 & 687 & 653 & 721 & 668 & 637 & 698 \\
\hline \multicolumn{13}{|c|}{$\begin{array}{l}\text { Households headed by person } \\
\text { of medium or high education level }\end{array}$} \\
\hline Risk-adjusted & 658 & 598 & 718 & 870 & 790 & 948 & 1014 & 925 & 1103 & 1000 & 930 & 1070 \\
\hline Actual & 942 & 868 & 1016 & 1235 & 1132 & 1338 & 1273 & 1176 & 1371 & 1215 & 1137 & 1293 \\
\hline
\end{tabular}

Source: Authors' estimates on the basis of data from the Permanent Household Survey (EPH).

\section{VII}

\section{Mobility and inequality}

This section of the article will evaluate the extent to which changes in income instability have been accompanied by changes in distributional inequality. As noted in section II, what has happened with income mobility is a key to assessing the relation between those two variables. The first part of this section will review the changes that have occurred in mobility, while the second will investigate how these have affected the income distribution.

\section{The evolution of income mobility}

As analysed above, in the early 1990s, household labour income became less variable, reflecting the impact of the macroeconomic stabilization programme applied until then. This coincided with a reduction in levels of income concentration, which had been very accentuated during the years of high inflation (see section II). Nonetheless, and despite the maintenance of price stability, household labour incomes gradually became more variable in the third and fourth phases (i.e. throughout the last half of the 1990s); and the same happened with inequality, which grew until the middle of that decade, before flattening out in the downswing phase.

Variability does not have to be accompanied by changes in the ranking of recipients' incomes, or even in the differentials between them. Nonetheless, such situations are unlikely to occur, since income variability usually results in changes in the relative positions of income recipients and/or in the gaps between their incomes, particularly when labourmarket events such as a period of unemployment are taken into account.

${ }^{23}$ Similar results are confirmed in the analysis by Cruces and Wodon (2003) for 1995-2002. 
Analysis of income mobility initially focused on the way households moved between income quintiles over the four observations. This data made it possible to identify different paths, which, following an established typology ${ }^{24}$ were classified as: flat, rising, falling, blip and zig-zag. The first included cases of households that remained in the same income quintile throughout the four observations, or moved at most to the immediately higher or lower level than at the start (irrespective of whether or not they returned to the original quintile). Rising (falling) paths are defined by households that move up (down) by at least two income quintiles with respect to the initial one, and either remain in that situation or rise (fall) further. The situation referred to as a "blip" included increases (decreases) of two or more quintiles from the initial one, followed by a return to the initial or even one quintile lower (higher) than at the start. Other more fluctuating alternatives are classified as zig-zag. This classification procedure makes it possible to describe the patterns of household mobility across defined thresholds (quintile boundaries).

Between the first and second phases, with the stabilization of the early 1990 s, the prevalence of flat paths increased from $55 \%$ to $59 \%$ of households, whereas the proportion of households experiencing blips decreased from $25 \%$ to $20 \%$ (table 7 ). The other categories were broadly unchanged. In the post-1995 recovery, inter-quintile paths reveal a substantial change in income mobility, with flat movements accounting for $72 \%$ of households while the other types of transition declined. Lastly, in the final recessionary phase, the previous mobility pattern was maintained, with the proportion of flat paths increasing again.

To complement the analysis, the Pearson and Spearman correlation coefficients were calculated for household incomes. Table 7 shows the average of the six coefficients that can be calculated from all observation pairs for each phase. ${ }^{25}$ Both correlation coefficients of household incomes increased in the last two phases (table 8), suggesting that not only did changes in the ranking of incomes decline, but the distances between them also narrowed, which is consistent with the results of the path analysis. In fact, the difference between the third- and fourth-phase coefficients was significantly larger than between the

\footnotetext{
${ }^{24}$ See, for example, Hills (1998) or Jarvis and Jenkins (1998).

25 The results of the comparison would not be altered by taking the average of the three coefficients that can be calculated between pairs of consecutive observations.
}

TABLE 7 Greater Buenos Aires: Mobility of household
labour incomes (Percentages)

\begin{tabular}{lcrrr}
\hline Paths & $\begin{array}{c}\text { High inflation } \\
\text { phase }\end{array}$ & $\begin{array}{c}\text { Stabilization } \\
\text { phase }\end{array}$ & $\begin{array}{c}\text { Recovery } \\
\text { phase }\end{array}$ & $\begin{array}{c}\text { Recession } \\
\text { phase }\end{array}$ \\
\hline Flat & 55.3 & 59.1 & 71.7 & 73.5 \\
Rising & 5.1 & 5.6 & 3.9 & 2.9 \\
Falling & 3.7 & 3.4 & 3.4 & 2.9 \\
Blip & 25.7 & 20.7 & 15.3 & 14.7 \\
Zig-zag & 10.2 & 11.3 & 5.7 & 6.1 \\
Total & 100 & 100 & 100 & 100 \\
\hline
\end{tabular}

Source: Authors' estimates on the basis of data from the Permanent Household Survey (EPH).

TABLE 8

Greater Buenos Aires: Correlation coefficients of household labour incomes ${ }^{a}$

\begin{tabular}{lcccc}
\hline $\begin{array}{l}\text { Households } \\
\text { headed by } \\
\text { individuals } \\
\text { under 65 of age }\end{array}$ & $\begin{array}{c}\text { High } \\
\text { inflation }\end{array}$ & $\begin{array}{c}\text { Stabilization } \\
\text { phase }\end{array}$ & $\begin{array}{c}\text { Recovery } \\
\text { phase }\end{array}$ & $\begin{array}{c}\text { Recession } \\
\text { phase }\end{array}$ \\
\hline Pearson & 0.695 & 0.715 & 0.817 & 0.875 \\
Spearman & 0.703 & 0.731 & 0.782 & 0.791 \\
\hline
\end{tabular}

Source: Authors' estimates on the basis of data from the Permanent Household Survey (EPH).

a All coefficients calculated between the two periods were significant at the $1 \%$ level. The amounts shown in the table are simple averages of the six coefficients that can be calculated between observation pairs of the second phase.

first and second phases. ${ }^{26}$ Increases were significant in the third phase (economic expansion following the "tequila" crisis), and they continued their rising trend in the final phase (table 8). In contrast, between the first and second phases, along with a steeper reduction in income variability, the income correlation was unchanged. This would reflect the generalization of the effects of controlling inflation and is compatible with the greater prevalence of flat income paths mentioned above. As will be recalled, the sharp rise in income correlation that occurred between the initial stabilization and economic recovery phases was accompanied by greater variability. This result demonstrates the need to

\footnotetext{
26 This emerges from a consideration of confidence intervals for the differences in correlations calculated by boot-strapping techniques. Such techniques are a statistical method for calculating the distribution of the estimator and confirming that a new sample gives the same result as the previous one.
} 
study the degree of mobility that accompanies instability, because the two do not always behave in the same way. What happened between the second and third phases analysed is indicative of that situation and reflects the fact that the differentials associated with changes in income narrowed, even as they were becoming increasingly frequent.

The combination of evidence that arises from the procedures used in this section reveals a process in which family labour income mobility has decreased since the late 1980s, which is consistent with a consolidation of the positions occupied by households in the income distribution. This means increasing segmentation between households of different types; and, in particular, it is becoming increasingly difficult for lower-income households to rise, either in absolute or in relative terms. This result is explained by the evolution of the labour market during the period in question. As mentioned when analysing the instability of individual incomes, there were increases in the degree of rotation between economic activity status and between occupations. This individual behaviour was largely projected on to households, given their revealed inability to implement compensation mechanisms in response to fluctuations in individual labour incomes.

\section{Distribution of current incomes and average incomes}

As described in the previous section, Argentina experienced a process of decreasing mobility of family incomes from the late 1980s and 1990s onwards. Secondly, section III showed that inequality in the distribution of current incomes has intensified since the mid-1990s. These two pieces of evidence suggest that the concentration of more permanent incomes expanded faster than that of current incomes. Put another way, income mobility affected the dynamic of inequality in the income distribution less and less intensely. To quantify this effect, an "adjustment of inequality for mobility" index was calculated, as described in the methodological note (section IV); and the Gini coefficient was used as the inequality index. ${ }^{27}$

The mobility adjustment made to inequality was around $8 \%$ for the set of households in the first phase (late 1980s/early 1990s) and was maintained at similar levels in the second phase, covering the first half of the 1990s (table 9). This index then dropped in the next two phases to a level of around 5\% in the second of them. In these phases, therefore, the discount for mobility was less than during periods of high inflation.

The fact that the correction of static inequality to take account of income mobility has become ever smaller reflects the aforementioned consolidation of household positions in the income distribution.

It can be concluded, therefore, that the increase in inequality since the mid-1990s, documented in several studies based on cross-section data, partly underestimated the increase in the concentration of permanent household incomes. The increase in inequality measured by the average of Gini coefficients grew by $11 \%$ between the second and last periods, while the concentration of average incomes rose by $14 \%$.

\footnotetext{
27 Similar results were obtained with other indicators of inequality.
}

TABLE 9

Greater Buenos Aires: Gini coefficients of the inequality of household labour incomes

\begin{tabular}{|c|c|c|c|c|c|c|c|c|c|c|c|c|}
\hline \multirow{3}{*}{ Total households } & \multicolumn{3}{|c|}{ High inflation phase } & \multicolumn{3}{|c|}{ Stabilization phase } & \multicolumn{3}{|c|}{ Recovery phase } & \multicolumn{3}{|c|}{ Recession phase } \\
\hline & \multirow[t]{2}{*}{$\begin{array}{l}\text { Coeffi- } \\
\text { cient }\end{array}$} & \multicolumn{2}{|c|}{$\begin{array}{l}\text { Confidence } \\
\text { interval }\end{array}$} & \multirow[t]{2}{*}{$\begin{array}{l}\text { Coeffi- } \\
\text { cient }\end{array}$} & \multicolumn{2}{|c|}{$\begin{array}{l}\text { Confidence } \\
\text { interval }\end{array}$} & \multirow[t]{2}{*}{$\begin{array}{l}\text { Coeffi- } \\
\text { cient }\end{array}$} & \multicolumn{2}{|c|}{$\begin{array}{l}\text { Confidence } \\
\text { interval }\end{array}$} & \multirow[t]{2}{*}{$\begin{array}{l}\text { Coeffi- } \\
\text { cient }\end{array}$} & \multicolumn{2}{|c|}{$\begin{array}{l}\text { Confidence } \\
\text { interval }\end{array}$} \\
\hline & & $\begin{array}{l}\text { Lower } \\
\text { bound }\end{array}$ & $\begin{array}{l}\text { Upper } \\
\text { bound }\end{array}$ & & $\begin{array}{l}\text { Lower } \\
\text { bound }\end{array}$ & $\begin{array}{l}\text { Upper } \\
\text { bound }\end{array}$ & & $\begin{array}{l}\text { Lower } \\
\text { bound }\end{array}$ & $\begin{array}{l}\text { Upper } \\
\text { bound }\end{array}$ & & $\begin{array}{l}\text { Lower } \\
\text { bound }\end{array}$ & $\begin{array}{l}\text { Upper } \\
\text { bound }\end{array}$ \\
\hline $\begin{array}{l}\text { Gini coefficient of } \\
\text { average income }\end{array}$ & 0.452 & 0.432 & 0.472 & 0.392 & 0.375 & 0.409 & 0.444 & 0.428 & 0.459 & 0.447 & 0.430 & 0.463 \\
\hline $\begin{array}{l}\text { Average of cross- } \\
\text { section Gini coefficients }\end{array}$ & 0.492 & 0.476 & 0.507 & 0.423 & 0.405 & 0.443 & 0.472 & 0.468 & 0.475 & 0.472 & 0.462 & 0.482 \\
\hline $\begin{array}{l}\text { Gini coefficient of risk- } \\
\text { adjusted average income } \\
\text { Coefficient } R \text { : Adjustment } \\
\text { of inequality for mobility }(\%)\end{array}$ & 0.491 & 0.469 & 0.513 & 0.441 & 0.423 & 0.460 & 0.497 & $\begin{array}{c}0.477 \\
-5.9\end{array}$ & 0.516 & 0.504 & $\begin{array}{c}0.487 \\
-5.4\end{array}$ & 0.521 \\
\hline
\end{tabular}

Source: Authors' estimates on the basis of data from the Permanent Household Survey (EPH). 
The analysis of risk-adjusted income inequality provides an overview that strengthens these results, since that measure of inequality changed in a similar yet more pronounced way than the average of actual incomes.

\section{VII}

\section{Conclusions}

The macroeconomic stabilization achieved in the early 1990s reduced the variability of family incomes. Nonetheless, the growth of occupational instability as from the middle of that decade meant that fluctuations in current family incomes persisted into the early twenty-first century and remained high, although less so than in the high inflation phase. It is worth noting here the differential impact of the reduction of inflation on households in the different strata. In the case of households headed by individuals with low levels of schooling, the stabilizing effect was fully discounted by occupational variability. When analysing individual incomes, the impact of that variability is greater, because there is no reduction in income instability for the group, which actually increases among employed persons of low education levels.

These patterns of current-income fluctuations are reflected in the difference between the behaviour of average family labour income and family labour income adjusted for risk, which was lower in low-strata households.

In conjunction with the (slight) reduction in the instability of household incomes recorded between the end phases analysed, the distances moved by family incomes became increasingly smaller. As a result, the positions of households in the income distribution tended to consolidate, causing growing segmentation between households of different types. The above shows that low-income families not only benefited less from income stabilization, but also faced additional difficulties in improving their relative position.

The panorama of growing inequality in the income distribution since the early 1990s, as reported by various studies based on current incomes, is also appropriate for describing what happened to changes in the distribution of more permanent incomes. Inequality in the latter actually increased slightly more than in current incomes, because of the decrease in mobility recorded throughout that period.

A general conclusion to be drawn from the analysis of this article is that inequality in the early 2000s was similar to that recorded in the late 1980s. An evaluation of this similarity should take account of the fact that periods of high inflation were accompanied by sharply worsening distribution. Even when the comparison is made with the third (growth) phase, rather than the final (recessionary) phase, there is no reduction compared to the years of hyperinflation.

This would appear to support the hypothesis that increasing differentiation in terms of labour instability accentuated the increase in inequality among more permanent incomes.

(Original: Spanish) 


\section{Bibliography}

Albornoz, F. and M. Menéndez (2002): Analyzing income mobility and inequality: the case of Argentina during the 1990's, Paris, unpublished.

Altimir, O. and L. Beccaria (2001): El persistente deterioro de la distribución del ingreso en Argentina, Desarrollo económico, vol. 40, No. 160, Buenos Aires, Institute of Economic and Social Development, January-March.

Arrow, K.J. (1970): Essays in the Theory of Risk Bearing, Amsterdam, North-Holland.

Atkinson, A. (1970): On the measurement of inequality, Journal of Economic Theory, vol. 2, No. 3, Amsterdam, Elsevier.

Beccaria, L. and F. Groisman (2005): Las familias ante los cambios en el mercado de trabajo, in L. Beccaria and R. Maurizio (eds.), Mercado de trabajo y equidad en Argentina, Buenos Aires, Prometeo.

Beccaria, L. and R. Maurizio (2004): Movilidad ocupacional en el Gran Buenos Aires, El trimestre económico, vol. 71, No. 283, Mexico City, Fondo de Cultura Económica.

Beccaria, L., V. Esquivel and R. Maurizio (2002): Desigualdad y polarización del ingreso en Argentina, Red pública, No. 2, Buenos Aires.

Burgess, S., K. Gardiner and others (2000): Measuring Income Risk, CASE Paper, No. 40, London, Centre for Analysis of Social Exclusion, London School of Economics.

Cowell, F. (2000): Measuring of inequality, in A. Atkinson and F. Bourguignon (eds.), Handbook of Income Distribution, Amsterdam, Elsevier.

Cruces, G. and Q. Wodon (2003): Risk-adjusted poverty in Argentina: measurement and determinants, Argentina Crisis and Poverty. A Poverty Assessment, vol. 2, Washington, D.C., World Bank.

Farber, H. (1999): Mobility and stability: the dynamics of job change in labor markets, in O. Ashenfelter and D. Card, Handbook of Labor Economics, Amsterdam, Elsevier.

Fields, G. (2004): Economic and Social Mobility are Really Multifaceted, Ithaca, School of Industrial and Labor Relations, Cornell University.
Fields, G. and M.L. Sánchez Puerta (2005): Remuneration Mobility in Urban Argentina, document prepared for the World Bank.

Fontenay, C. de, T. Gorgens and H. Liu (2002): The role of mobility in offsetting inequality: a non parametric exploration of CPS, Review of Income and Wealth vol. 48, No. 3, Oxford, United Kingdom, Blackwell Publishing.

Galiani, S. and H. Hopenhayn (2000): Duración y riesgo de desempleo en Argentina, Mercado de Trabajo y Relaciones Industriales series, Buenos Aires, Fundación Argentina para el Desarrollo con Equidad (FADE), unpublished.

Gottschalk, P. and S. Danziger (1998): Family income mobility: how much is there and has it changed?, in J.A. Auerbach and R.S. Belows (eds.), The Inequality Paradox: Growth of Income Disparity, Washington, D.C., National Policy Association.

Gutiérrez, F. (2004): Dinámica salarial y ocupacional. Análisis de panel para Argentina: 1998-2002, working paper, No. 11, La Plata, Universidad Nacional de La Plata.

Hills, J. (1998): Does income mobility mean that we do not need to worry about poverty?, in A. Atkinson and J. Hills (eds.), Exclusion, Employment and Opportunity, London, Centre for Analysis of Social Exclusion, London School of Economics.

Hopenhayn, H. (2001): Labor Market Policies and Employment Duration: The Effects of Labor Market Reform in Argentina, Research Net Working Papers, No. R.407, Washington, D.C., Inter-American Development Bank, February.

Jarvis, S. and S. Jenkins (1998): How much income mobility is there in Britain?, Economic Journal, vol. 108, Oxford, United Kingdom, Blackwell Publishing.

Nickel, S., T. Jones and G. Quintini (2000): A Picture of Job Insecurity Facing British Men, London, Centre for Economic Performance.

OECD (Organisation for Economic Co-operation and Development) (1996): Employment Outlook, Paris.

Shorrocks, A.F. (1978): Income inequality and income mobility, Journal of Economic Theory, vol. 19, No. 2, Amsterdam, Elsevier. 